\title{
Matrix-Isolated Monomeric Tryptophan: Electrostatic Interactions as Nontrivial Factors Stabilizing Conformers
}

\author{
A. Kaczor, ${ }^{*}, \dagger, *$ I. D. Reva, ${ }^{\dagger}$ L. M. Proniewicz, ${ }^{\ddagger}$ and R. Fausto ${ }^{\dagger}$ \\ Department of Chemistry, University of Coimbra, P-3004-535 Coimbra, Portugal, and \\ Faculty of Chemistry, Jagiellonian University, Ingardena 3, 30-060 Krakow, Poland
}

Received: January 5, 2007; In Final Form: February 6, 2007

\begin{abstract}
An extensive analysis of the conformational space of tryptophan (Trp) was performed at the B3LYP/6-311++G(d,p) level and verified by comparison with the infrared spectra of the compound isolated in low-temperature argon and xenon matrixes. Different types of conformers have been unequivocally identified in the matrixes. Type I exhibits the trans arrangement of the carboxylic group and is stabilized by an $\mathrm{O}-\mathrm{H} \cdots \mathrm{N}$ intramolecular $\mathrm{H}$-bond. Types II and III have the carboxylic group in the cis conformation and feature $\mathrm{N}-\mathrm{H} \cdots \mathrm{O}=\mathrm{C}$ and $\mathrm{N}-\mathrm{H} \cdots \mathrm{O}-\mathrm{C}$ hydrogen bonds, respectively. Three individual conformers of type I were identified in the matrixes. Other conformational degrees of freedom are related with the $\mathrm{C}_{\alpha}-\mathrm{C}_{\beta}-\mathrm{C}_{\gamma}=\mathrm{C}$ and $\mathrm{C}_{1}-\mathrm{C}_{\alpha}-\mathrm{C}_{\beta}-\mathrm{C}_{\gamma}$ angles $\left(\chi_{1}\right.$ and $\chi_{2}$, respectively). In proteins, these two dihedral angles define the conformations of the amino acid residues. In monomeric Trp, $\chi_{1}$ adopts the "+" (ca. $\left.+90^{\circ}\right)$ and "-" (ca. $-90^{\circ}$ ) orientations, while average values of $-67.4,170.5$, and $67.6^{\circ}$ ("a", "b", and "c", respectively) were found for $\chi_{2}$. Theoretical analysis revealed two important factors in stabilizing the structures of the Trp conformers: the H-bond type and electrostatic interactions. Classified by the H-bond type, the most stable are forms I, followed by II and III. Out of possible combinations of the $\chi_{1}$ and $\chi_{2}$ dihedral angles, "a+", "b+", and "c-" were theoretically found more stable than their "a-", "b-", and "c+" counterparts. Thus, the stabilizing effect of interactions involving the pyrrole ring (which are possible in $\mathrm{Ia}+, \mathrm{Ib}+$, and $\mathrm{Ic}-$ conformers) is considerably higher compared to those in which the phenyl ring is engaged (existing in the $\mathrm{Ia}-, \mathrm{Ib}-$, and Ic+ forms).
\end{abstract}

\section{Introduction}

L-Amino acids are molecules of fundamental meaning from the point of view of life sciences, as they are the constituting units of the natural polypeptide and protein chains. They also take part in a variety of fundamental biochemical processes, such as, for example, neurotransmission, enzymatic catalysis, and synthesis of other bioactive compounds. Zwitterionic forms of amino acids are stabilized in the crystalline state and in solution. ${ }^{1-3}$ On the other hand, proteins' structures are based on amino acids in their nonionic (neutral) form. The neutral form of amino acids is also found in the gas phase $\mathrm{e}^{4-12}$ and low-temperature inert matrixes, ${ }^{13-23}$ which has stimulated extensive investigation of amino acids' structures under these conditions.

The majority of early experimental studies concentrated on matrix isolation of amino acids with aliphatic side chains, such as glycine, ${ }^{13,14}$ alanine, ${ }^{15,16}$ leucine,${ }^{24}$ valine, ${ }^{17}$ or proline. ${ }^{18,19}$ Only more recently, amino acids with higher conformational freedom, as serine, ${ }^{20,21}$ tyrosine,${ }^{22}$ and phenylalanine, ${ }^{23}$ have been isolated in cryogenic matrixes and investigated. On the other hand, extensive studies of aromatic amino acids have been performed in the gaseous phase (seeded free jet expansion) by laser spectroscopy ${ }^{8-11,25-27}$ due to presence of UV chromophores in their side chains. The important point of analyzing the monomeric neutral amino acids is that conformations of side chains in proteins generally correspond to conformers of low energy. ${ }^{28}$

* Corresponding author. E-mail: kaczor@chemia.uj.edu.pl.

¿ University of Coimbra.

$\doteqdot$ Jagiellonian University.
The most stable structures of aliphatic amino acids have been found to be stabilized by a bifurcated H-bond linking the carbonyl oxygen atom with the hydrogen atoms of the amino group. On the other hand, the $\mathrm{O}-\mathrm{H} \cdots \mathrm{N}$ hydrogen bond and the carboxylic group in the trans conformation have been found in the lowest energy conformers of phenylalanine and tryptophan studied in a supersonic beam, ${ }^{8,11}$ as well as in the two aromatic amino acids previously studied by matrix-isolation spectroscopy (phenylalanine and tyrosine). ${ }^{22,23}$ The stabilization of the abovementioned conformers has been attributed to the existence of a "daisy-chain" sequence of interactions involving the aromatic $\pi$-electrons, the amino group, and the carboxylic $\mathrm{OH}$ group. ${ }^{8}$

In general, the conformational picture of amino acids, both in the gas phase and isolated in low-temperature matrixes, is considerably complicated, ${ }^{4-21}$ particularly for the amino acids with high rotational freedom or numerous plausible intramolecular H-bonds, as the aromatic amino acids ${ }^{8,11,22,23}$ and serine. ${ }^{20}$ Quantum-chemical calculations, used as main analytical tool ${ }^{29-31}$ or as support for the experimental work, $, 8,11,12,20,23,32$ have been shown to be of fundamental importance in analyzing the complicated conformational space of these flexible molecules. As for other amino acids, most of the experimental conformational studies on Trp were supported by theoretical calculations of molecular dipole moments, rotational constants, and vibrational spectra. ${ }^{11,12,32}$ Purely theoretical conformational studies of monomeric tryptophan are rather scarce. ${ }^{29,31}$

Six conformers of phenylalanine have been identified in a supersonic beam by UV-UV hole-burning and ion-dip spectroscopy ${ }^{8}$ as well as in an argon matrix. ${ }^{23}$ Tyrosine has not been conformationally characterized in detail, although Ramaekers 


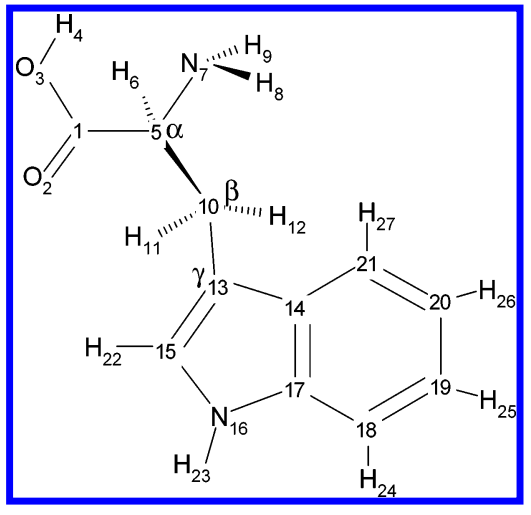

Figure 1. Numbering scheme of the Trp molecule. Carbon atoms are represented by their numbers.

et al. ${ }^{22}$ considered a possible contribution of nine structures to the spectra of the matrix-isolated compound. Some discrepancies are found for tryptophan studied in a supersonic beam; Snoek et al. ${ }^{11}$ identified six and five forms of the compound in the UV-UV hole-burning and ion-dip IR spectra at $210{ }^{\circ} \mathrm{C}$, respectively, while only three conformers have been determined in the ion-dip spectra reported by Bakker et al. ${ }^{12}$ The existence of five forms of tryptophan rapidly cooled to $0.38 \mathrm{~K}$ in helium droplets was shown by high-resolution vibrational spectroscopy. ${ }^{33}$ However, it was also shown that if the compound is introduced in the molecular beam and is cooled slowly to 85 $\mathrm{K}$, then the vast majority of molecules relax to the most stable conformer. $^{32}$ These results demonstrate that the number of conformational states experimentally observable depends on the sample temperature and on sample history. The fast cooling makes possible the experimental observation of higher energy conformers of Trp. ${ }^{33,34}$

Matrix isolation also permits the fast cooling of the gaseous compound, and thus, it can also be used to study higher energy molecular conformational states. One important feature of the matrix-isolation studies of amino acids is the usually observed strong dependence of the conformational distribution on the heights of the barriers for conformational interconversion under the chosen experimental conditions. . $^{23,35,36}$ Additionally, the application of quite high temperatures to sublimate these compounds (ca. $200{ }^{\circ} \mathrm{C}$ ) results in complicated conformational mixtures, by increasing the relative abundance of higher energy conformers in the gaseous phase prior to matrix deposition. Interestingly, it has also been demonstrated that the relative conformational populations are strongly affected by entropy factors, as it was clearly shown for L-phenylalanine. ${ }^{23}$ Therefore, the study of amino acids, particularly those exhibiting a large number of internal degrees of freedom, requires extensive support of calculations, including consideration of energy barriers for conformational interconversion and entropy effects. This methodology, coupled with matrix-isolation infrared spectroscopy, has been successfully applied in the study of the conformational behavior of L-phenylalanine, ${ }^{23}$ allowing the structural analysis of the compound and attribution of its infrared spectra in a low-temperature argon matrix. Unlike tyrosine and phenylalanine, no studies on matrix-isolated tryptophan have been reported hitherto. The conformational and vibrational analyses of the compound isolated in both argon and xenon matrixes are then presented in this work. The interpretation of the experimental data was supported by extensive DFT(B3LYP) calculations with the polarized split valence triple- $\zeta$ 6-311++G(d,p) basis set.

\section{Methods}

2.1. Experimental Section. L-Tryptophan (purity $\geq 99.0 \%$ ) was purchased from Merck Sp. z o.o. (Warsaw, Poland) and used without further purification.

Infrared spectra were recorded in the $4000-400 \mathrm{~cm}^{-1}$ range using a Mattson Infinity 60AR series FT-IR spectrometer, with $0.5 \mathrm{~cm}^{-1}$ resolution. The compound was sublimated at $463-$ $478 \mathrm{~K}$ from a home-made minifurnace assembled inside the cryostat. The hot vapor of tryptophan was shock-frozen on a cooled CsI window, together with a large excess of gaseous argon (N60, Air Liquide) or xenon (N48, Air Liquide) coming from a separate line kept at room temperature. The temperature of the optical substrate $(11-12 \mathrm{~K}$ for argon and $11-12$ or 20 $\mathrm{K}$ for xenon) was obtained using an APD Cryogenics closedcycle helium refrigeration system with a DE-202A expander. The temperature was measured directly at the sample holder by a silicon diode temperature sensor, connected to a digital controller (Scientific Instruments, model 9650-1), with accuracy of $0.1 \mathrm{~K}$. Annealing of the matrixes was performed by increasing the temperature stepwise, using increments of $3-5$ and $4 \mathrm{~K}$, up to 41 and $72 \mathrm{~K}$ for argon and xenon, respectively. During the annealing, spectra were collected at each intermediate temperature.

2.2. Computational Section. The DFT calculations were carried out with the three-parameter density functional B3LYP, 37,38 using the $6-311++\mathrm{G}(\mathrm{d}, \mathrm{p})$ basis set. Geometry optimizations were carried out under the tight criteria. A total of 42 minima of Trp were found, with 17 of them in the $10 \mathrm{~kJ} \mathrm{~mol}^{-1}$ energy range relative to the most stable form. Vibrational spectra and thermochemical properties (at 298.15 and $473.15 \mathrm{~K}$ ) were computed for all calculated conformers. The equilibrium conformational populations characteristic of these two temperatures were estimated using the $\Delta G^{\circ}=-R T \ln K_{\mathrm{c}}$ equation, where $\Delta G^{\circ}$ is the standard Gibbs free energy relative to the most stable conformer and $K_{\mathrm{c}}$ is the ratio of the concentrations of the conformer in question relative to the most stable one.

Additionally, the geometries and energies of transition states for conformational interconversions were computed with the STQN $^{39,40}$ method (QST3 variation) for chosen pairs of conformers differing by internal rotation around the $\mathrm{C}_{1}-\mathrm{C}_{\alpha}$, $\mathrm{C}_{\beta}-\mathrm{C}_{\gamma}$, or $\mathrm{C}_{\alpha}-\mathrm{N}$ bond. Geometry optimizations were followed by calculations of the vibrational spectra at the same theory level. The nature of the obtained stationary points on the potential energy surface was checked through the analysis of the corresponding Hessian matrix. The transition states were characterized by presence of one imaginary frequency. The transition states between conformers differing in the conformation of the carboxylic group ( $\mathrm{cis}$ or trans $\mathrm{O}=\mathrm{C}-\mathrm{O}-\mathrm{H}$ configuration) were not investigated, since the barrier associated with the $\mathrm{C}-\mathrm{O}$ internal rotation has been shown to be high for amino acids and similar carboxylic acids, e.g., more than $5500 \mathrm{~cm}^{-1}$ $\left(66 \mathrm{~kJ} \mathrm{~mol}^{-1}\right)$ for glycine, ${ }^{4} 53 \mathrm{~kJ} \mathrm{~mol}^{-1}$ for glycolic acid, ${ }^{41}$ and ca. $50 \mathrm{~kJ} \mathrm{~mol}^{-1}$ for phenylalanine. ${ }^{23}$

Calculated harmonic frequencies were used in the analysis of the experimental spectra. They were scaled down by a factor of 0.98 , to account mainly for anharmonicity effects and limitations of the basis set. The scaling factor was chosen to provide a better agreement between the experimental and theoretical spectra in the fingerprint region. The scaling factor used in this study was the same as in our previous work on phenylalanine. ${ }^{23}$ All the above-mentioned calculations were performed using the GAUSSIAN03 ${ }^{42}$ suite of programs. Potential energy distributions (PED) of the normal modes were 


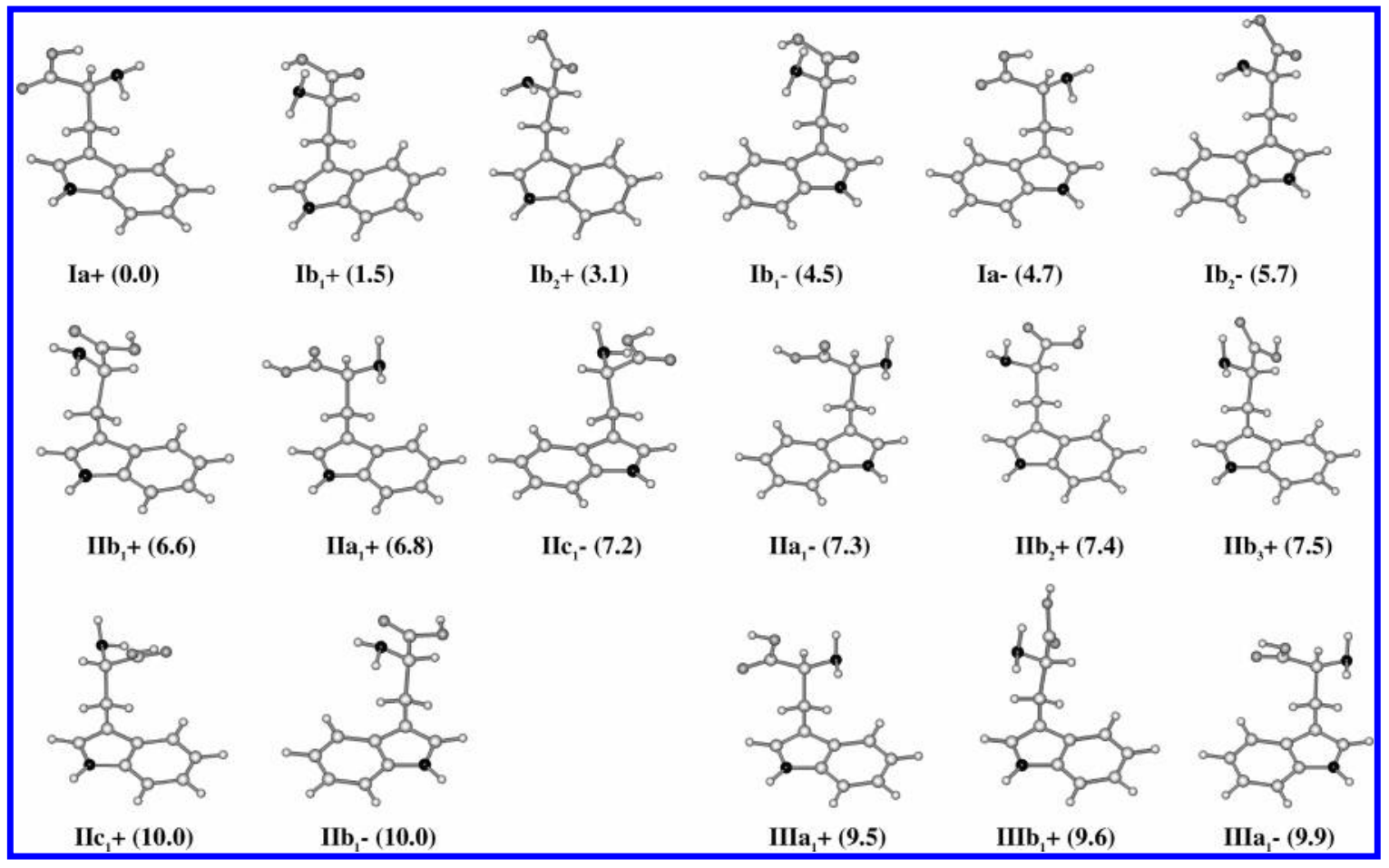

Figure 2. B3LYP/6-311++G(d,p)-optimized geometries of the most stable Trp conformers. For the naming system, refer to the Geometries, Energies, and Entropic Factors section. The zero-point-corrected energy values (in kJ mol ${ }^{-1}$ ) relative to the most stable form are given in parentheses.

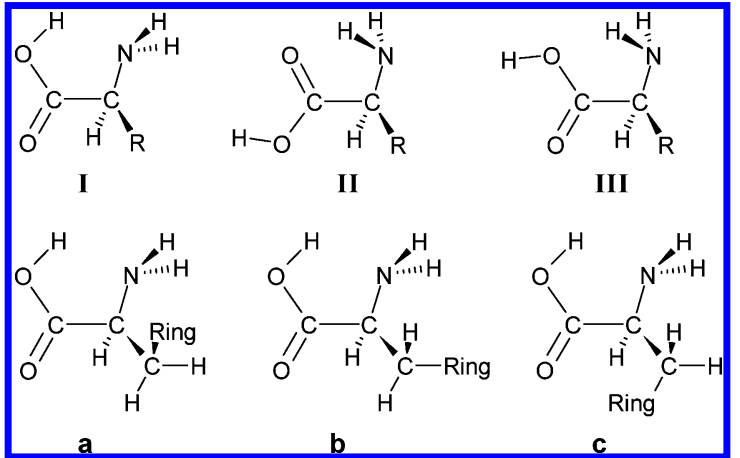

Figure 3. Top row: Conformer types resulting from different orientations of the amino acid fragment (I-III). "R" is used for the side chain. Bottom row: Conformer types $(\mathrm{a}-\mathrm{c})$ resulting from different orientations of the side chain (exemplified for type I conformers). "Ring" is used for the indole ring.

computed in terms of natural internal coordinates ${ }^{43}$ with the GAR2PED program. ${ }^{44}$

\section{Results and Discussion}

3.1. Geometries, Energies, and Entropic Factors. The molecular structure of Trp monomer with the adopted atomnumbering scheme is shown in Figure 1.

The input structures of Trp conformers used in the geometry optimizations were created from previously found phenylalanine minima, ${ }^{23}$ replacing the phenyl group by the indole group. Asymmetry of the indole ring doubles the number of conceivable input structures relative to phenylalanine, as two values of the torsion angle linking the alanyl side chain and the indole ring are possible, ca. +90 and $-90^{\circ} .{ }^{45}$

The most stable conformers of the compound optimized at the B3LYP/6-311++G(d,p) level of theory are presented in Figure 2, while the dihedral angles defining all conformers found on the potential energy surface of Trp are given in Table 1. The naming system of conformers is adopted after the one introduced for phenylalanine (Phe). ${ }^{23}$ The first element in the name of a conformer is designated by Roman numerals I-III. In type $\mathrm{I}$, the $\mathrm{O}=\mathrm{C}-\mathrm{O}-\mathrm{H}$ dihedral angle adopts the trans orientation (ca. $180^{\circ}$ ), whereas types II and III correspond to the cis orientation $\left(\mathrm{ca} .0^{\circ}\right)$. Type I conformers are stabilized by an intramolecular $\mathrm{O}-\mathrm{H} \cdots \mathrm{N}$ hydrogen bond, whereas type II and III conformers possess the $\mathrm{N}-\mathrm{H} \cdots \mathrm{O}=\mathrm{C}$ and $\mathrm{N}-\mathrm{H} \cdots \mathrm{O}-\mathrm{C}$ intramolecular hydrogen bonds, respectively (Figure 3 ). The second element of the conformer's name is the letter "a", "b", or "c", which describes the relative position of the indole ring with respect to the amino acid fragment. This parameter is described by the value of the $\mathrm{C}_{1}-\mathrm{C}_{\alpha}-\mathrm{C}_{\beta}-\mathrm{C}_{\gamma}$ dihedral angle (in proteins it is commonly denoted as $\chi_{1}$ ) which adopts essentially three possible orientations centered on average values of $-67.4^{\circ}$ (a), $170.5^{\circ}$ (b), and $67.6^{\circ}$ (c) (see Table 1). These typical values of $\chi_{1}$ found for tryptophan are very close to those found for phenylalanine ${ }^{23}$ and valine. ${ }^{17}$ The third element in the conformer's name is given by an Arabic numeral, " 1 ", " 2 ", or " 3 ". It corresponds to three different orientations of the lone pair (lp) of the nitrogen atom with respect to the $\mathrm{C}_{\alpha}-\mathrm{N}$ axis in conformers of types II and III. They are not related to any particular value of the dihedral angle $\mathrm{C}_{1}-\mathrm{C}_{\alpha}-\mathrm{N}-\mathrm{lp}$ but correspond to increasing relative energies. In the conformers of type I, the position of the lone pair corresponds approximately to the cis orientation with respect to the $\mathrm{C}_{1}-\mathrm{C}_{\alpha}$ bond (absolute value around $25.4^{\circ}$ ), because of the existence of the intramolecular hydrogen bond between the $\mathrm{OH}$ and $\mathrm{NH}_{2}$ groups (Table 1).

Formally, an additional degree of freedom exists in Phe monomer; it is related to the orientation of the phenyl ring with respect to the alanyl fragment. This parameter was not included into the naming system of Phe, since the corresponding dihedral angle $\left(\mathrm{C}_{\alpha}-\mathrm{C}_{\beta}-\mathrm{C}_{\gamma}=\mathrm{C}\right)$ falls within a very narrow range of values close to $90^{\circ} .{ }^{23}$ The structures where this dihedral angle is equal to +90 or $-90^{\circ}$ are degenerated in Phe owing to the local symmetry of the phenyl ring. On the contrary, in Trp the indole ring is asymmetric and an additional parameter is needed to specify the orientation of the alanyl side chain relatively to 
TABLE 1: Relative Energies $\left(\Delta E_{\text {corr }}, \mathrm{kJ} \mathrm{mol}^{-1}\right.$; Including Zero-Point Vibrational Corrections), Dipole Moments ( $\mu$, D), and Main Dihedral Angles (degrees) of the Trp Conformers ${ }^{a}$

\begin{tabular}{|c|c|c|c|c|c|c|c|}
\hline name & $\Delta E_{\text {corr }}$ & $\mu$ & $\mathrm{O}=\mathrm{C}-\mathrm{O}-\mathrm{H}$ & $\mathrm{C}_{1}-\mathrm{C}_{\alpha}-\mathrm{C}_{\beta}-\mathrm{C}_{\gamma}$ & $\mathrm{C}_{1}-\mathrm{C}_{\alpha}-\mathrm{N}-\mathrm{lp}$ & $\mathrm{O}=\mathrm{C}_{1}-\mathrm{C}_{\alpha}-\mathrm{N}$ & $\mathrm{C}_{\alpha}-\mathrm{C}_{\beta}-\mathrm{C}_{\gamma}-$ ring \\
\hline $\mathrm{Ia}+$ & 0.0 & 3.7 & 178.1 & -70.2 & -24.6 & -167.6 & 82.7 \\
\hline $\mathrm{Ib}_{1}+$ & 1.5 & 7.2 & -178.4 & 177.7 & 29.7 & 165.9 & 109.1 \\
\hline $\mathrm{Ib}_{2}+$ & 3.1 & 7.2 & 179.6 & 172.2 & -23.4 & -169.6 & 109.0 \\
\hline $\mathrm{Ib}_{1}-$ & 4.5 & 6.6 & -178.5 & 176.8 & 31.0 & 165.5 & -85.1 \\
\hline $\mathrm{Ia}-$ & 4.7 & 7.0 & 180.0 & -79.2 & -17.7 & -173.5 & -98.7 \\
\hline $\mathrm{Ib}_{2}-$ & 5.7 & 6.3 & 179.4 & 172.0 & -26.1 & -168.3 & -86.3 \\
\hline $\mathrm{IIb}_{1}+$ & 6.6 & 3.3 & -0.8 & 177.1 & -74.5 & -30.3 & 103.1 \\
\hline $\mathrm{IIa}_{1}+$ & 6.8 & 3.0 & 0.6 & -63.2 & -175.1 & -1.1 & 95.6 \\
\hline $\mathrm{IIc}_{1}-$ & 7.2 & 2.1 & -1.0 & 63.1 & 174.9 & -66.3 & -100.5 \\
\hline $\mathrm{IIa}_{1}-$ & 7.3 & 1.3 & -1.1 & -66.3 & -178.8 & -5.5 & -84.9 \\
\hline $\mathrm{IIb}_{2}+$ & 7.4 & 1.2 & -1.0 & 164.0 & 162.3 & -22.1 & 91.1 \\
\hline $\mathrm{IIb}_{3}+$ & 7.5 & 2.2 & 0.2 & 175.1 & 81.4 & 11.5 & 99.2 \\
\hline $\mathrm{IIIa}_{1}+$ & 9.5 & 2.3 & 0.1 & -67.0 & -173.6 & -171.4 & 93.1 \\
\hline $\mathrm{IIIb}_{1}+$ & 9.6 & 3.0 & 1.5 & 173.4 & 62.2 & -138.9 & 103.5 \\
\hline $\mathrm{IIIa}_{1}-$ & 9.9 & 3.1 & 2.3 & -71.2 & -176.2 & 170.4 & -91.2 \\
\hline $\mathrm{IIc}_{1}+$ & 10.0 & 3.1 & -3.8 & 61.2 & 173.2 & -44.5 & 89.7 \\
\hline $\mathrm{IIb}_{1}-$ & 10.0 & 4.1 & -0.7 & 178.4 & -73.3 & -31.0 & -86.6 \\
\hline $\mathrm{IIIb}_{2}+$ & 10.6 & 4.5 & -1.6 & 172.4 & -60.5 & 142.4 & 103.0 \\
\hline $\mathrm{IIb}_{3}-$ & 10.6 & 4.0 & 0.1 & 173.0 & 81.2 & 13.0 & -97.4 \\
\hline $\mathrm{IIIc}_{1}-$ & 11.0 & 3.1 & -0.5 & 60.4 & 179.3 & 108.1 & -102.7 \\
\hline $\mathrm{IIc}_{2}-$ & 11.7 & 2.3 & 0.1 & 63.1 & -58.4 & -62.0 & -101.2 \\
\hline $\mathrm{IIb}_{2}-$ & 12.3 & 3.2 & -1.0 & 155.6 & 161.5 & -21.8 & -108.6 \\
\hline $\mathrm{Ic}_{1}-$ & 12.4 & 2.9 & 173.9 & 85.0 & -33.6 & -156.4 & -80.4 \\
\hline $\mathrm{IIIb}_{1}-$ & 12.5 & 3.4 & 1.5 & 171.4 & 64.8 & -140.5 & -94.1 \\
\hline $\mathrm{IIIb}_{3}+$ & 12.8 & 3.3 & 0.5 & 161.0 & 170.2 & 140.2 & 95.4 \\
\hline $\mathrm{Ic}_{2}-$ & 13.2 & 3.4 & -174.6 & 68.9 & 34.2 & 158.0 & -99.0 \\
\hline $\mathrm{IIIb}_{2}-$ & 13.5 & 3.0 & -1.6 & 174.4 & -60.0 & 141.0 & -87.1 \\
\hline $\mathrm{IIIc}_{1}+$ & 13.6 & 0.9 & 1.8 & 56.6 & 179.4 & 113.3 & 77.4 \\
\hline $\mathrm{IIc}_{2}+$ & 14.1 & 3.8 & -2.7 & 62.9 & -67.8 & -47.9 & 88.2 \\
\hline $\mathrm{IIIc}_{2}-$ & 14.5 & 1.5 & 1.7 & 75.7 & 59.5 & -114.5 & -94.1 \\
\hline $\mathrm{IIa}_{2}+$ & 14.7 & 3.1 & 0.6 & -66.9 & -70.2 & -22.0 & 88.4 \\
\hline $\mathrm{IIa}_{2}-$ & 15.1 & 2.9 & -1.6 & -58.5 & -73.1 & -20.3 & -82.9 \\
\hline $\mathrm{IIIc}_{3}-$ & 16.1 & 3.5 & -2.5 & 60.8 & -50.1 & 119.0 & -101.7 \\
\hline $\mathrm{IIIa}_{2}-$ & 16.5 & 4.2 & 1.6 & -67.1 & -56.3 & 159.0 & -91.3 \\
\hline $\mathrm{IIIa}_{2}+$ & 17.2 & 2.5 & 0.0 & -63.9 & -56.7 & 169.0 & 92.6 \\
\hline $\mathrm{IIIb}_{3}-$ & 17.4 & 0.9 & 0.5 & 152.9 & 169.4 & 138.0 & -107.4 \\
\hline $\mathrm{Ic}_{3}-$ & 18.6 & 4.9 & -172.4 & 72.6 & -176.1 & -1.1 & -112.9 \\
\hline $\mathrm{IIIc}_{3}+$ & 18.7 & 2.9 & -0.6 & 57.2 & -53.1 & 121.7 & 78.8 \\
\hline $\mathrm{IIc}_{3}-$ & 19.2 & 3.1 & 1.0 & 85.4 & 84.4 & 21.2 & -107.9 \\
\hline $\mathrm{Ic}_{2}+$ & 19.8 & 5.8 & -172.5 & 59.9 & 36.9 & 153.4 & 83.3 \\
\hline $\mathrm{IIIc}_{2}+$ & 22.5 & 4.1 & 1.2 & 80.2 & 58.3 & -104.2 & 86.3 \\
\hline $\mathrm{Ic}_{3}+$ & 24.1 & 5.3 & -174.3 & 69.4 & -172.1 & 2.7 & 51.3 \\
\hline
\end{tabular}

a "lp" states for the lone electron pair of the nitrogen atom, and $\mathrm{C}_{1}-\mathrm{C}_{\alpha}-\mathrm{N}-\mathrm{lp}$ is defined by the plane bisecting the $\mathrm{C}_{1}-\mathrm{C}_{\alpha}-\mathrm{N}-\mathrm{H}_{8}$ and $\mathrm{C}_{1}-\mathrm{C}_{\alpha}-\mathrm{N}-\mathrm{H}_{9}$ dihedral angles.

TABLE 2: Energy Differences between Pairs of Trp Conformers Differing by the Orientation of the Alanyl Side Chain Relative to the Indole Ring ${ }^{a}$

\begin{tabular}{lllr}
\hline \multicolumn{1}{c}{ type } & I & II & \multicolumn{1}{c}{ III } \\
\hline a or $\mathrm{a}_{1}$ & 4.7 & 0.5 & 0.4 \\
$\mathrm{a}_{2}$ & & 0.4 & -0.7 \\
$\mathrm{~b}_{1}$ & 3.0 & 3.4 & 2.9 \\
$\mathrm{~b}_{2}$ & 2.6 & 4.9 & 2.9 \\
$\mathrm{~b}_{3}$ & & 3.1 & 4.6 \\
$\mathrm{c}_{1}$ & & -2.8 & -2.6 \\
$\mathrm{c}_{2}$ & -6.6 & -2.4 & -8.0 \\
$\mathrm{c}_{3}$ & -5.5 & & -2.6
\end{tabular}

${ }^{a}$ Energy differences are given in $\mathrm{kJ} \mathrm{mol}^{-1}$, with respect to the "plus" conformer $\left(\mathrm{C}_{5}-\mathrm{C}_{10}-\mathrm{C}_{13}-\mathrm{C}_{15} \geq 90^{\circ}\right)$.

the indole ring. Thus, the structures where the $\mathrm{C}_{\alpha}-\mathrm{C}_{\beta}-\mathrm{C}_{\gamma}=\mathrm{C}$ dihedral angle (denoted in proteins as $\chi_{2}$ ) assumes values around +90 and $-90^{\circ}$ are designated by the plus $(+)$ and the minus (-) symbol, respectively.

It is interesting to note that the conformational degrees of freedom of the side chain denoted as "a", "b", and "c", as well as "+" and "-", persist also in the amino acid residues in peptides, while the conformational features distinguishing conformers of types I-III lose significance after formation of polypeptide chains. ${ }^{46}$ That is why the side chain conformational preferences gain a special importance from the biological point of view. For example, the possibility of changing between different $\chi_{1}(+$ and -$)$ and $\chi_{2}(\mathrm{a}-\mathrm{c})$ orientations is frequently used as a probe for exploring the conformation of the protein in time-resolved fluorescence measurements, like for the tryptophan residue situated in the DNA-binding domain of the tetracycline repressor. ${ }^{47}$

If the zero-point correction is not taken into account, the 10 Trp lowest energy conformers are predicted by the calculations to fall in the range of $0-10 \mathrm{~kJ} \mathrm{~mol}^{-1}$. This result is comparable with those obtained previously by Snoek et al., ${ }^{11}$ who identified 10 and 9 low-energy conformers of Trp at the B3LYP/6-31+G(d) and MP2/6-31+G(d) levels of theory, respectively, and by Huang and $\operatorname{Lin},{ }^{29}$ who found 8 and 9 minima at the B3LYP/6-311G(d) and MP2/6-311++G(d,p) levels, respectively.

If the zero-point correction is included, 17 conformers are in the range of $0-10 \mathrm{~kJ} \mathrm{~mol}^{-1}$ with respect to the most stable $\mathrm{Ia}+$ form (cf. Figure 2). The six most stable forms are of type $\mathrm{I}$, i.e., have the $\mathrm{O}=\mathrm{C}-\mathrm{O}-\mathrm{H}$ dihedral angle in the trans orientation. As it was shown before, ${ }^{8,11,22,23}$ the stabilization of conformers of this type is characteristic of aromatic amino acids, contrary to the aliphatic family, where the conformers with the 
TABLE 3: Relative Zero-Point-Corrected Energies $\left(\Delta E_{\text {corr }}, \mathrm{kJ} \mathrm{mol}^{-1}\right)$, Enthalpies $\left(\Delta H_{473}, \mathrm{~kJ} \mathrm{~mol}^{-1}\right)$, Entropic Contributions $\left(\mathrm{T} \Delta S_{473}, \mathrm{~kJ} \mathrm{~mol}^{-1}\right)$, Standard Gibbs Free Energies $\left(\Delta G^{\circ}, \mathrm{kJ} \mathrm{mol}^{-1}\right)$, and Abundances of the Most Stable Trp Conformers Calculated on the Basis of $\Delta G^{\circ}$ Values $(\%)$

\begin{tabular}{|c|c|c|c|c|c|c|c|c|}
\hline conformer $^{a}$ & $\Delta E_{\text {corr }}^{b}$ & $\Delta H_{473^{c}}{ }^{c}$ & $T \Delta S_{473^{c}}$ & $\Delta G^{\circ}{ }_{473^{c}}$ & $\Delta G^{\mathrm{o}}{ }_{298^{d}}$ & $\%_{473^{e}}$ & $\%_{473 \mathrm{~A}^{f}}$ & $\%_{298^{g}}$ \\
\hline $\mathrm{Ia}+$ & 0.0 & 0.0 & 0.0 & 0.0 & 0.0 & 8.2 & 8.2 & 21.9 \\
\hline $\mathrm{Ib}_{1}+$ & 1.5 & 1.8 & -1.2 & 0.6 & 1.0 & 7.0 & 17.5 & 14.6 \\
\hline $\mathrm{Ib}_{2}+$ & 3.1 & 4.0 & -5.0 & -1.0 & 0.8 & 10.5 & 0.0 & 15.6 \\
\hline $\mathrm{Ib}_{1}-$ & 4.5 & 5.0 & -1.9 & 3.1 & 3.8 & 3.7 & 9.6 & 4.8 \\
\hline $\mathrm{Ia}-$ & 4.7 & 4.7 & 1.6 & 6.3 & 5.7 & 1.6 & 1.6 & 2.2 \\
\hline $\mathrm{Ib}_{2}-$ & 5.7 & 6.7 & -5.4 & 1.3 & 3.2 & 5.9 & 0.0 & 5.9 \\
\hline $\mathrm{IIb}_{1}+$ & 6.6 & 8.4 & -5.2 & 3.1 & 4.9 & 3.7 & 3.7 & 3.0 \\
\hline $\mathrm{IIa}_{1}+$ & 6.8 & 8.4 & -4.2 & 4.2 & 5.6 & 2.8 & 2.8 & 2.3 \\
\hline $\mathrm{IIc}_{1}-$ & 7.2 & 9.2 & -9.7 & -0.5 & 2.9 & 9.3 & 9.3 & 6.7 \\
\hline $\mathrm{IIa}_{1}-$ & 7.3 & 8.9 & -4.4 & 4.5 & 6.0 & 2.6 & 2.6 & 1.9 \\
\hline $\mathrm{IIb}_{2}+$ & 7.4 & 9.8 & -11.3 & -1.4 & 2.6 & 11.8 & 11.8 & 7.7 \\
\hline $\mathrm{IIb}_{3}+$ & 7.5 & 9.5 & -6.4 & 3.1 & 5.4 & 3.7 & 3.7 & 2.5 \\
\hline $\mathrm{IIII}_{1}+$ & 9.5 & 11.4 & -5.6 & 5.7 & 7.5 & 1.9 & 1.9 & 1.1 \\
\hline $\mathrm{IIIb}_{1}+$ & 9.6 & 11.5 & -7.1 & 4.4 & 6.9 & 2.7 & 2.7 & 1.4 \\
\hline $\mathrm{IIIa}_{1}-$ & 9.9 & 11.4 & -3.2 & 8.1 & 9.2 & 1.0 & 1.0 & 0.5 \\
\hline $\mathrm{IIc}_{1}+$ & 10.0 & 11.9 & -5.1 & 6.7 & 8.5 & 1.5 & 1.5 & 0.7 \\
\hline $\mathrm{IIb}_{1}-$ & 10.0 & 11.9 & -6.0 & 5.9 & 8.0 & 1.8 & 1.8 & 0.9 \\
\hline $\mathrm{IIIb}_{2}+$ & 10.6 & 12.6 & -6.9 & 5.7 & 8.1 & 1.9 & 1.9 & 0.8 \\
\hline $\mathrm{IIb}_{3}-$ & 10.6 & 12.4 & -4.5 & 7.9 & 9.4 & 1.1 & 1.1 & 0.5 \\
\hline $\mathrm{IIIc}_{1}-$ & 11.0 & 13.0 & -7.0 & 6.0 & 8.4 & 1.8 & 1.8 & 0.7 \\
\hline $\mathrm{IIc}_{2}-$ & 11.7 & 13.9 & -8.9 & 5.0 & 8.2 & 2.3 & 2.3 & 0.8 \\
\hline $\mathrm{IIb}_{2}-$ & 12.3 & 14.5 & -7.4 & 7.1 & 9.7 & 1.3 & 1.3 & 0.4 \\
\hline $\mathrm{Ic}_{1}-$ & 12.4 & 12.9 & -3.0 & 9.9 & 11.0 & 0.7 & 0.7 & 0.3 \\
\hline $\mathrm{IIIb}_{1}-$ & 12.5 & 14.2 & -5.7 & 8.5 & 10.5 & 0.9 & 0.9 & 0.3 \\
\hline $\mathrm{IIIb}_{3}+$ & 12.8 & 15.3 & -10.9 & 4.4 & 8.3 & 2.7 & 2.7 & 0.8 \\
\hline $\mathrm{Ic}_{2}-$ & 13.2 & 14.0 & -4.0 & 9.9 & 11.4 & 0.7 & 0.7 & 0.2 \\
\hline $\mathrm{IIIb}_{2}-$ & 13.5 & 15.5 & -6.8 & 8.6 & 11.0 & 0.9 & 0.9 & 0.3 \\
\hline $\mathrm{IIIc}_{1}+$ & 13.6 & 15.7 & -7.3 & 8.4 & 11.0 & 1.0 & 1.0 & 0.3 \\
\hline $\mathrm{IIc}_{2}+$ & 14.1 & 16.0 & -5.1 & 10.9 & 12.7 & 0.5 & 0.5 & 0.1 \\
\hline $\mathrm{IIIc}_{2}-$ & 14.5 & 16.4 & -6.1 & 10.3 & 12.4 & 0.6 & 0.6 & 0.1 \\
\hline $\mathrm{IIa}_{2}+$ & 14.7 & 17.1 & -9.1 & 8.0 & 11.2 & 1.1 & 1.1 & 0.2 \\
\hline $\mathrm{IIa}_{2}-$ & 15.1 & 17.0 & -4.3 & 12.7 & 14.2 & 0.3 & 0.3 & 0.1 \\
\hline $\mathrm{IIIc}_{3}-$ & 16.1 & 18.4 & -8.2 & 10.3 & 13.1 & 0.6 & 0.6 & 0.1 \\
\hline $\mathrm{IIIa}_{2}-$ & 16.5 & 18.2 & -3.4 & 14.7 & 15.9 & 0.2 & 0.2 & 0.0 \\
\hline $\mathrm{IIIa}_{2}+$ & 17.2 & 18.7 & -4.0 & 14.7 & 16.0 & 0.2 & 0.2 & 0.0 \\
\hline $\mathrm{IIIb}_{3}-$ & 17.4 & 19.6 & -8.8 & 10.8 & 13.9 & 0.5 & 0.5 & 0.1 \\
\hline $\mathrm{Ic}_{3}-$ & 18.6 & 20.5 & -5.5 & 14.9 & 16.9 & 0.2 & 0.2 & 0.0 \\
\hline $\mathrm{IIIc}_{3}+$ & 18.7 & 21.0 & -6.8 & 14.2 & 16.5 & 0.2 & 0.2 & 0.0 \\
\hline $\mathrm{IIc}_{3}-$ & 19.2 & 21.3 & -8.9 & 12.4 & 15.6 & 0.3 & 0.3 & 0.0 \\
\hline $\mathrm{Ic}_{2}+$ & 19.8 & 20.7 & -4.0 & 16.7 & 18.1 & 0.1 & 0.1 & 0.0 \\
\hline $\mathrm{IIIc}_{2}+$ & 22.5 & 24.5 & -7.5 & 17.0 & 19.6 & 0.1 & 0.1 & 0.0 \\
\hline $\mathrm{Ic}_{3}+$ & 24.1 & 25.9 & -7.1 & 18.8 & 21.3 & 0.1 & 0.1 & 0.0 \\
\hline
\end{tabular}

${ }^{a}$ B3LYP/6-311++G(d,p); all structures have $C_{1}$ symmetry. ${ }^{b} E_{\text {corr }}=-686.349143$ hartree for conformer Ia+. ${ }^{c} H, S$, and $G$ values calculated at $473.15 \mathrm{~K}\left(G_{473}=-686.425536\right.$ and $H_{473}=-686.316890$ hartree for conformer Ia +$){ }^{d} G$ values calculated at $298.15 \mathrm{~K}\left(G_{298}=-686.389509\right.$ hartree for conformer Ia+). ${ }^{e}$ Abundance of conformers at $473.15 \mathrm{~K} .{ }^{f}$ Abundance of conformers at $473.15 \mathrm{~K}$ including expected interconversion of conformers, $\mathrm{Ib}_{2}+\rightarrow \mathrm{Ib}_{1}+$ and $\mathrm{Ib}_{2}-\rightarrow \mathrm{Ib}_{1}-.{ }^{g}$ Abundance of conformers at $298.15 \mathrm{~K}$.

carboxylic group in the cis orientation and the bifurcated $\mathrm{N}-\mathrm{H} \cdots \mathrm{O}=\mathrm{C}$ bond are of lower energy. ${ }^{14-19}$ The chain of interactions involving $\mathrm{OH}$ and $\mathrm{NH}_{2}$ groups as well as $\pi$-electrons was previously given as the reason for the increased stabilization of type I conformers of $\mathrm{Phe}^{8}$ and Trp, ${ }^{8,11}$ despite the unfavorable trans conformation of the carboxylic group in their structures.

The geometries of the alanyl chain and of the indole ring of "plus" and "minus" counterparts are quite similar for a given Trp pair of conformers (cf. Table 1). Nevertheless, significant differences are observed in their relative energy. Trp conformers of both $\mathrm{a}+$ and $\mathrm{b}+$ type are considerably more stable than the respective $a-$ and $b-$ forms. This regularity persists through the whole population of Trp conformers, with the single exception of the IIIa 2 pair (cf. Table 2). Conversely, c- forms are stabilized in all cases compared with their $\mathrm{c}+$ counterparts. Although the H-bond type is the decisive factor determining the relative energies of Trp conformers, there are also various electrostatic interactions influencing in a significant way the energy of the different forms. These are mainly interactions of the carbonyl oxygen atom with protons of the pyrrole ring (A) or the phenyl ring (B) but also interactions of the hydroxyl oxygen atom with the protons of the pyrrole ring $(\mathrm{C})$ or the phenyl ring (D) and interactions of the amino protons with the pyrrole ring $(\mathrm{E})$ or phenyl ring $(\mathrm{F})$. Interactions involving the pyrrole ring are the common structural factor of $a+, b+$, and $\mathrm{c}-$ forms, while their counterparts $(\mathrm{a}-, \mathrm{b}-$, and $\mathrm{c}+$ forms $)$ are dominated by interactions involving the phenyl ring. For example, the forms involving the A-type interaction $\left(\mathrm{Ia}+, \mathrm{IIc}_{1}-\right.$, $\left.\mathrm{IIIa}_{1}+\right)$ are of lower energy than their counterparts $\left(\mathrm{Ia}-, \mathrm{IIc}_{1}+\right.$, $\left.\mathrm{IIIa}_{1}-\right)$, where the B-type interactions are prevailing. Similarly, $\mathrm{II}_{1}+$ is stabilized relative to $\mathrm{IIa}_{1}-$ (C vs D interaction). In $\mathrm{Ib}_{1}+$, $\mathrm{Ib}_{2}+, \mathrm{IIb}_{1}+$, or $\mathrm{IIIb}_{1}+$ forms, where the $\mathrm{A}-\mathrm{D}$ interplay is not possible, the contributing factor is the weaker $\mathrm{E}$ interaction involving the $\pi$ electrons of the pyrrole ring. The E interaction lowers the energies of these conformers compared to their counterparts $\left(\mathrm{Ib}_{1}-, \mathrm{Ib}_{2}-, \mathrm{IIb}_{1}-\right.$, or $\left.\mathrm{IIIb}_{1}-\right)$, where the F-type interactions involving the $\pi$ density of the phenyl ring exists instead.

Considerable differences in the predicted stability of the conformers are noticed when Trp is compared with Phe. ${ }^{23}$ The "minus" Trp conformers of group I have the same order of stability and similar relative energy values as the three most 
stable forms of Phe, as the stabilizing interactions are of the same type (involving the phenyl ring; see Figure 2). The interactions with the pyrrole ring considerably stabilize the "plus" Trp conformers of type I, leading also to reversal in the relative energy of these forms (energy increases in the order $\mathrm{Ia}+<\mathrm{Ib}_{1}+<\mathrm{Ib}_{2}+$ ). Under standard conditions, the total abundance of $\mathrm{I}+$ forms (ca. 52\%) is, therefore, much higher than that of the I- conformers (ca. 13\%); cf. Table 3. Conformations of amino acid residues in protein side chains are usually close to "low-energy conformers". ${ }^{28}$ In agreement with this, the preference for the "plus" forms $\left(\mathrm{C}_{\alpha}-\mathrm{C}_{\beta}-\mathrm{C}_{\gamma}=\mathrm{C}\right.$ angle between +70 and $+110^{\circ}$ ) over the "minus" ones $\left(\mathrm{C}_{\alpha}-\mathrm{C}_{\beta}-\mathrm{C}_{\gamma}=\mathrm{C}\right.$ dihedral angle between -70 and $\left.-110^{\circ}\right)$ is clearly noticed for Trp residues in proteins. Indeed, a search in the PDB database brought ca. $38 \%$ of "plus" forms and only ca. 24\% of the "minus" conformers, over 110000 Trp residues analyzed. ${ }^{28} \mathrm{~A} \mathrm{C}_{\alpha}-\mathrm{C}_{\beta}-\mathrm{C}_{\gamma}=\mathrm{C}$ dihedral angle in the range -30 to $+30^{\circ}$ was found in only ca. $11 \%$ of the residues (off-rotamers) and ascribed to conformations stabilized by $\mathrm{C}-\mathrm{H} \cdots \mathrm{X}$ interactions, where $\mathrm{X}$ is a polar hydrogen-bond acceptor or $\pi$ electron system. ${ }^{28}$ The above-mentioned $\mathrm{C}-\mathrm{H} \cdots \mathrm{X}$ interactions have been shown to be the most significant factors stabilizing these offrotamers. ${ }^{28}$ Similarly, weak electrostatic interactions of $\mathrm{A}-\mathrm{F}$ type have also considerable impact on the energy of the Trp monomers.

Significant influence of entropy on stabilization of specific conformers has been previously demonstrated for Phe. ${ }^{23}$ From the experimental point of view, this factor gains additional importance for Trp, as the temperature necessary to sublimate Trp is even higher than in the case of Phe (ca. $463 \mathrm{~K}$ versus $423 \mathrm{~K}$ for the latter).

It is also important to mention that in principle the matrix media might also change in some extent the stability of the conformers. However, fortunately, in the present case the most stable conformers (type I) are the most polar forms (as shown in Table 1) with an average dipole moment over 6 D. It is then easily to conclude that any additional matrix-induced stabilization of these conformers should not change the qualitative picture here presented. In addition, the fact that we were still able to observe less polar conformers of types II and III (as described in detail below) indicates that the matrix-induced changes of conformers' properties should not be very large for this compound and, in particular, conformer interconversion barriers are not substantially different from those calculated for the gaseous phase.

The most stable conformer Ia+, as well as its counterpart $\mathrm{Ia}-$, are both entropically destabilized with respect to all other forms (cf. Table 2). In general, forms "a" (type I) and "a 1 " (types II and III) are enthalpically favored but entropically destabilized. This is basically attributed to the presence of the strong $\mathrm{H}$-bonding system in their structures. Additionally, more flexible conformers, with virtually absent or very weak interactions between the amino and carboxylic groups and the ring system, are favored by entropy, with the forms $\mathrm{IIb}_{2}+, \mathrm{IIIb}_{3}+$, and $\mathrm{IIc}_{1}-$ being the most significantly stabilized by this factor $\left(T \Delta S_{473}=\right.$ $-11.3,-10.9,-9.7 \mathrm{~kJ} \mathrm{~mol}^{-1}$ relative to Ia + , respectively). The dependence of the entropic stabilization on the H-bond strength and on the restriction of the side chain rotation is well exemplified for the $\operatorname{IIc}_{1}(+$ and -$)$ structures. In both these forms the carbonyl oxygen atom interacts with ring hydrogen atom(s) (of pyrrole or phenyl ring, for $\mathrm{IIc}_{1}-$ and $\mathrm{IIc}_{1}+$, respectively), but in the "minus" form the interaction is much weaker than in the "plus" one $[(\mathrm{C}=) \mathrm{O} \cdots \mathrm{H}$ distance equals to 3.309 and $2.843 \AA$, respectively]. Additionally, the $\mathrm{C}=\mathrm{O} \cdots \mathrm{H}-\mathrm{N}$

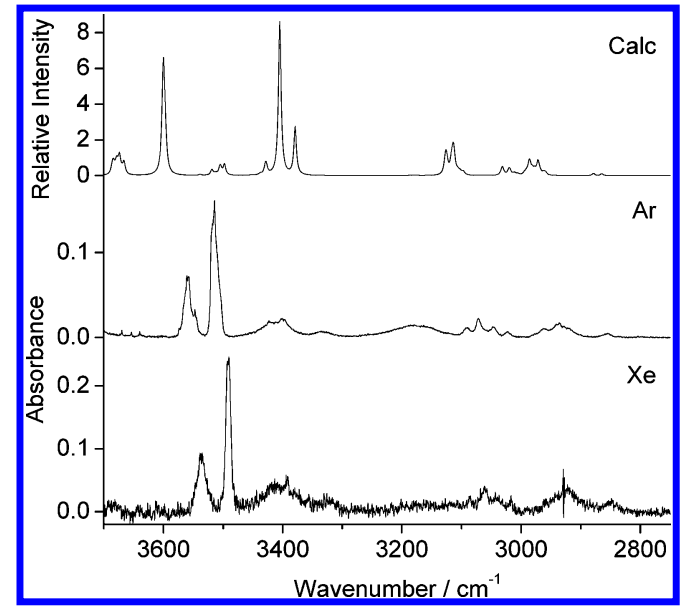

Figure 4. FT-IR spectra of Trp isolated in solid xenon (Xe, $11 \mathrm{~K}$, bottom) and argon (Ar, $11 \mathrm{~K}$, middle) in the $3700-2750 \mathrm{~cm}^{-1}$ range, along with the theoretical simulated spectrum obtained by summing the spectra of 12 individual conformers scaled by respective computed abundances at $473 \mathrm{~K}$ (Calc, top).

hydrogen bond is slightly stronger in the case of conformer $\mathrm{IIc}_{1}+$ (the $\mathrm{O} \cdots \mathrm{H}$ distance is equal to 2.637 and $2.806 \AA$ for $\mathrm{IIc}_{1}+$ and $\mathrm{IIc}_{1}-$, respectively). Both above-mentioned factors contribute to a considerably higher entropic stabilization of the $\mathrm{IIc}_{1}-$ form relatively to the $\mathrm{IIc}_{1}+$ conformer $\left(T \Delta S_{473}=-9.7 \mathrm{~kJ} \mathrm{~mol}^{-1}\right.$ vs $-5.1 \mathrm{~kJ} \mathrm{~mol}^{-1}$, relative to Ia + ).

The heights of the relevant barriers for internal rotation have been calculated to predict the possible isomeric conversion processes that may take place during matrix deposition or in the matrix, influencing the observed conformational distribution. The barriers for conversions involving change of one dihedral angle have been considered. Only the most stable conformers have been taken into account due to the negligible abundance of higher energy species. Two barriers, both shown to be connected with the rotation of the amino group, were found to be extremely low. The first barrier separates isomer $\mathrm{Ib}_{2}+$ from $\mathrm{Ib}_{1}+$, and it is equal to ca. $0.2 \mathrm{~kJ} \mathrm{~mol}^{-1}$. The second barrier is the counterpart in the "minus" structures, being related with the conversion of form $\mathrm{Ib}_{2}-$ into $\mathrm{Ib}_{1}-\left(0.3 \mathrm{~kJ} \mathrm{~mol}^{-1}\right)$. The conversions between these conformers should take place immediately during the deposition of the matrix due to conformational cooling, ${ }^{48-50}$ thus eliminating both $\mathrm{Ib}_{2}$ forms in favor of $\mathrm{Ib}_{1}$ isomers. Additionally, there are quite low-energy barriers predicted for the $\mathrm{IIb}_{2}+\rightarrow \mathrm{IIb}_{1}+\left(5.4 \mathrm{~kJ} \mathrm{~mol}^{-1}\right.$, rotation around the $\mathrm{C}_{\alpha}-\mathrm{N}$ bond $)$ and $\mathrm{IIIb}_{1}+\rightarrow \mathrm{IIb}_{3}+\left(6.6 \mathrm{~kJ} \mathrm{~mol}^{-1}\right.$, rotation around the $\mathrm{C}_{1}-\mathrm{C}_{\alpha}$ bond) conversions, which suggest possible occurrence of these conformational isomerizations during annealing or/and deposition of the matrix. Other calculated barriers are predicted to be higher than $10 \mathrm{~kJ} \mathrm{~mol}^{-1}$, and the conformational relaxation processes associated with these barriers can be considered to be improbable at the present experimental conditions. ${ }^{48-50}$

3.2. IR Spectrum of Matrix-Isolated Trp. The FT-IR spectra of tryptophan isolated in argon and xenon at $11 \mathrm{~K}$, in the $3700-2750,1900-1200$, and $1200-400 \mathrm{~cm}^{-1}$ ranges, are presented in Figures 4-6, respectively. They are compared with the calculated spectrum obtained by coadding the theoretically predicted spectra of 12 individual conformers with equilibrium abundances higher than $2 \%$ at $473 \mathrm{~K}$ (cf. Table 3). The abundance of two forms, namely $\mathrm{Ib}_{1}+$ and $\mathrm{Ib}_{1}-$, has been augmented at the expense of the abundances of conformers $\mathrm{Ib}_{2}+$ and $\mathrm{Ib}_{2}-$, respectively, to account for very low isomerization barriers predicted (see the previous section) for the conversion of the first pair of conformers into the second pair. ${ }^{51}$ 


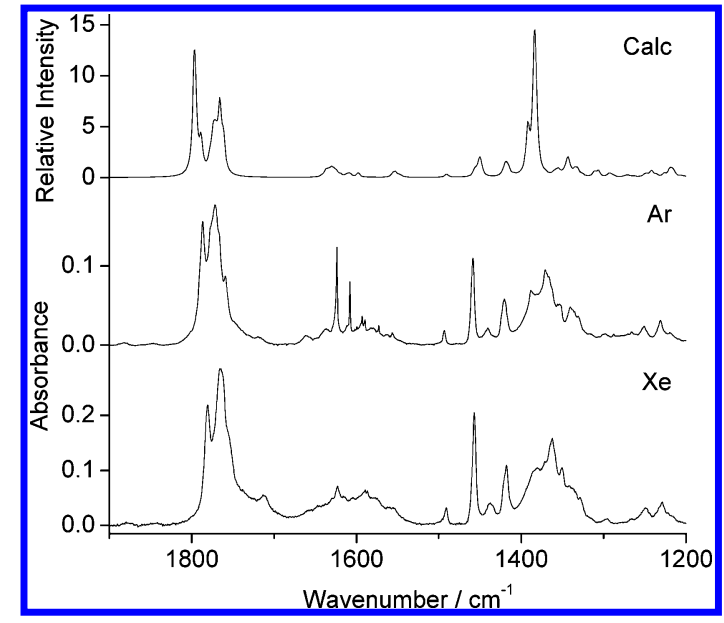

Figure 5. FT-IR spectra of Trp isolated in solid xenon $(\mathrm{Xe}, 11 \mathrm{~K}$, bottom) and argon (Ar, $11 \mathrm{~K}$, middle) in the $1900-1200 \mathrm{~cm}^{-1}$ range, along with the theoretical spectrum obtained by summing the spectra of 12 individual conformers scaled by respective computed abundances at $473 \mathrm{~K}$ (Calc, top).

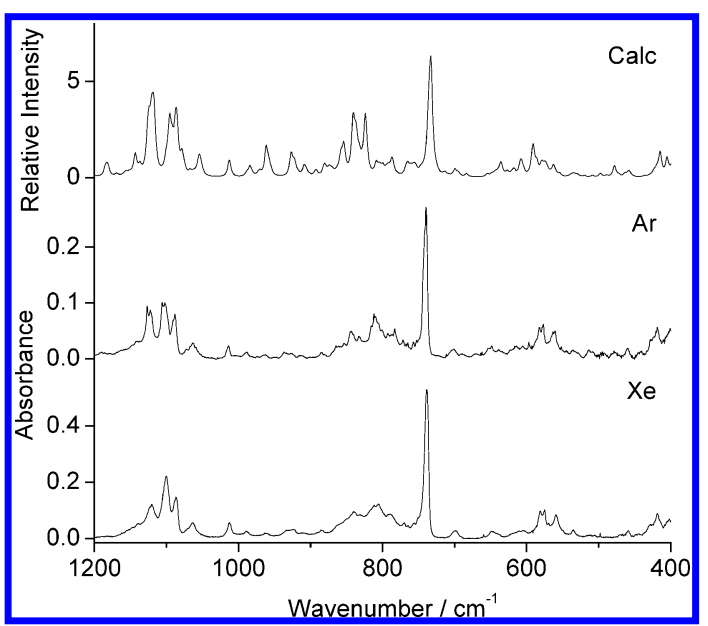

Figure 6. FT-IR spectra of Trp isolated in solid xenon (Xe, $11 \mathrm{~K}$, bottom) and argon (Ar, $11 \mathrm{~K}$, middle) in the $1200-400 \mathrm{~cm}^{-1}$ range, along with the theoretical spectrum obtained by summing the spectra of 12 individual conformers scaled by respective computed abundances at $473 \mathrm{~K}$ (Calc, top).

Moreover, accounting for the spectra of conformers with contributions lower than $2 \%$ does not influence the result of superposition, implying that these forms can be neglected in the analysis, although the fraction of abundance neglected in the analysis of the spectra amounts to ca. $25 \%$. The specific consequence of the strong influence of entropy on the Gibbs free energy values of Trp is the stabilization of conformers that are not necessarily the lowest in energy $\left(\mathrm{as} \mathrm{IIb}_{2}+\right.$ and $\mathrm{IIc}_{1}-$ ).

The full assignment of the spectra is given in Table 2S, while Table 1S gives the definition of internal coordinates used in the normal-mode analysis of Trp. It is, however, necessary to emphasize that the presented assignment has to be treated as tentative due to strong overlap of the bands due to different conformers of Trp contributing to the experimental spectra.

The key bands in the vibrational analysis of Trp are due to the $\mathrm{O}-\mathrm{H}$ and $\mathrm{C}=\mathrm{O}$ stretching vibrations as well as to the bending of the $\mathrm{C}-\mathrm{O}-\mathrm{H}$ group. Although the agreement of experimental and calculated spectra is slightly worse in the $\mathrm{O}-\mathrm{H} / \mathrm{N}-\mathrm{H}$ stretching range, due to the anharmonicity of these vibrational modes (harmonic calculations and the single scaling factor were applied) and band broadening, a careful analysis of the observed profile allowed for the assignment of the experi- mental spectra. In particular, the intense band due to the welllocalized $v\left(\mathrm{~N}_{16}-\mathrm{H}_{23}\right)$ stretching mode around $3500-3510 \mathrm{~cm}^{-1}$ (in argon) acts as an adequate internal reference to a correct band assignment in this spectral range. This band is originated in the $\mathrm{N}-\mathrm{H}$ bond of the indole group, which is not involved in any intramolecular hydrogen bond, and is then predicted to appear in all conformers to within $1 \mathrm{~cm}^{-1}$ (Table 2S). The cumulative calculated intensity of this band in all conformers (ca. $60 \mathrm{~km} \mathrm{~mol}^{-1}$ ) is in agreement with the observed intense and narrow band ascribed to this vibration. The absorptions attributed to $\mathrm{O}-\mathrm{H}$ stretching vibrations are observed in two different regions, above and below the intense band ascribed to the $v(\mathrm{~N}-\mathrm{H})$ indole stretching: $3580-3530 \mathrm{~cm}^{-1}(\mathrm{Ar}) / 3560-$ $3510 \mathrm{~cm}^{-1}$ (Xe) and $3280-3110 \mathrm{~cm}^{-1}(\mathrm{Ar}) / 3240-3105 \mathrm{~cm}^{-1}$ (Xe). The frequency, as well as profile of the absorptions (bands in the lower frequency range are considerably broad) allows ascribing them to two different types of conformers: with the $\mathrm{OH}$ group (i) non-H-bonded and (ii) H-bonded. The latter are associated with conformers of type I (calcd: 3405, 3404, and $3379 \mathrm{~cm}^{-1}$ ), while the former are attributed to the structures of types II and III (calcd: $3586-3666 \mathrm{~cm}^{-1}$; cf. Table $2 \mathrm{~S}$ ). The effect of the $\mathrm{O}-\mathrm{H} \cdots \mathrm{N}$ hydrogen bonding interaction is the shift of the $\mathrm{C}-\mathrm{O}-\mathrm{H}$ bending vibration to higher frequency along with the increase of its intensity. Indeed, three different absorptions at 1388, 1371, and 1367 (shoulder) $\mathrm{cm}^{-1}$ are observed in the argon matrix and, more clearly, in xenon at 1380,1371 , and $1366 / 1362 \mathrm{~cm}^{-1}$. According to the calculations, these absorptions can be ascribed only to $\delta(\mathrm{C}-\mathrm{O}-\mathrm{H})$ vibrations of type I conformers (calcd: 1392, 1385, $1383 \mathrm{~cm}^{-1}$ ). Therefore, three different conformers of type I can be identified in the spectrum of Trp in the matrixes. This observation is in exact agreement with our theoretical prediction: (i) conformer Iais not detectable because of a very low population; (ii) two $\mathrm{Ib}_{2}$ conformers have low conversion barriers to their $\mathrm{Ib}_{1}$ counterparts (of lower energy). Therefore, three out of the total of six type I conformers can be neglected, the remaining three forms corresponding to the experimentally observed species.

Presence of conformers of type II and III could be also unequivocally proved in our experiments. The matrix-isolation spectra clearly show absorption bands in the $\mathrm{C}=\mathrm{O}$ stretching region at ca. 1778, 1772, 1767, and $1759 \mathrm{~cm}^{-1}$ for Ar and 1766, 1762 , and $1756 \mathrm{~cm}^{-1}$ for $\mathrm{Xe}$, which are characteristic of conformers II and III (calcd: $1778-1761 \mathrm{~cm}^{-1}$ ). The presence of both these types of Trp conformers in the molecular gaseous supersonic jet has been previously suggested. ${ }^{11,12}$ Although the sublimation temperatures did not differ significantly between the present matrix isolation and previous seeded beam ${ }^{11}$ or helium nanodroplet ${ }^{33}$ experiments, the strikingly different process of isolation of the analyte seems to significantly change the observed conformational picture of Trp. The matrix isolation "freezes" the population of an analyte at temperatures of sublimation, while supersonic jet expansion leads to adiabatic cooling and suppression of higher rotational and rovibrational levels, so that a thermal distribution corresponding to a temperature much lower than the temperature of sublimation is quickly achieved. Under the supersonic jet conditions, one could expect to be able to observe a smaller number of conformers, compared to the gaseous phase. In a matrix isolation experiment at least some additional higher energy conformers can be shockfrozen and experimentally observed. This picture is consistent with the larger number of conformers of tryptophan observed in this study.

The presence of different forms of the compound in the matrixes was corroborated by the annealing experiments. Figure 


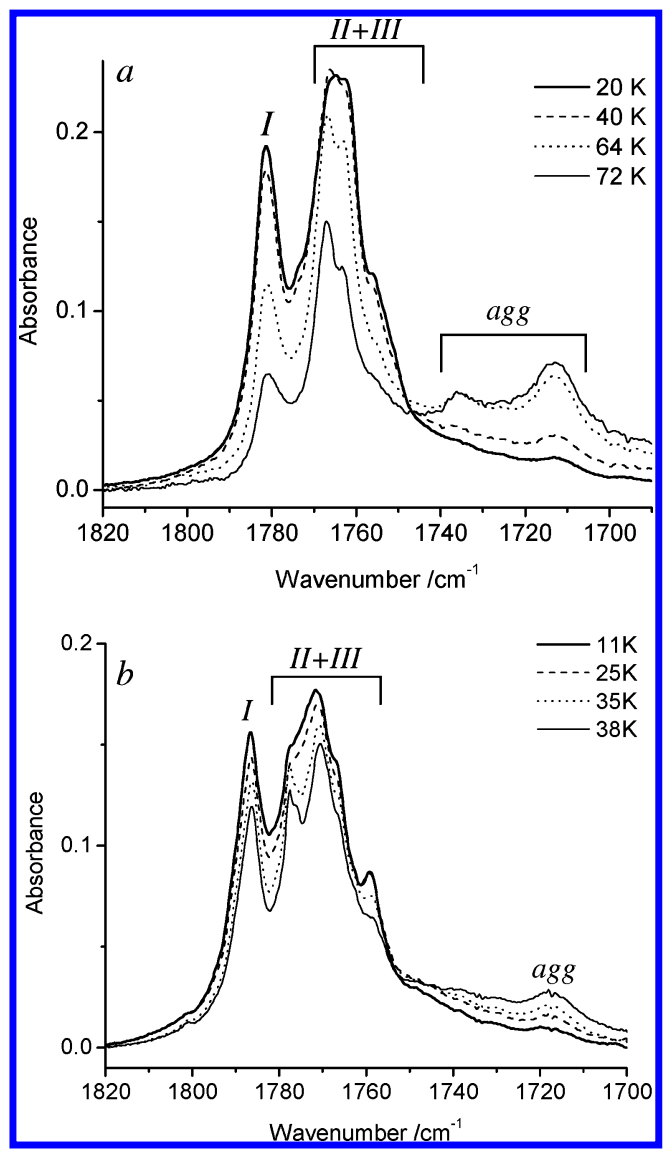

Figure 7. Carbonyl stretching region of the FT-IR spectra (as-deposited and annealed) of Trp isolated in solid xenon (a) and argon (b). I-III and agg denote absorptions associated with conformers of type I-III and aggregates of the compound, respectively.

7a shows the carbonyl stretching region of Trp isolated in a xenon matrix: as-deposited (at $20 \mathrm{~K}$ ) and annealed to 40, 64, and $72 \mathrm{~K}$. According to the calculations, the band at $1781 \mathrm{~cm}^{-1}$ is assigned to the $\mathrm{C}=\mathrm{O}$ stretching vibration of type I conformers only, while the group of bands at lower wavenumbers (at 1766, 1762, and $\left.1756 \mathrm{~cm}^{-1}\right)$ are ascribed to $v(\mathrm{C}=\mathrm{O})$ of type II (predominantly, due to their significantly higher abundance) and type III conformers.

Clearly, the main process occurring in the matrix upon annealing is the aggregation of the compound. It manifests itself as reduction of intensity of all monomeric bands observed upon increase of the temperature. However, a different temperature dependence of the absorption at $1781 \mathrm{~cm}^{-1}$, compared with the group of absorptions at 1766,1762 , and $1756 \mathrm{~cm}^{-1}$, is observed. The intensity of the absorption at $1781 \mathrm{~cm}^{-1}$ is decreasing already during annealing of the matrix at $40 \mathrm{~K}$, with further decrease upon annealing to higher temperatures. On the other hand, the group of bands at ca. $1760 \mathrm{~cm}^{-1}$ does not change in intensity up to $40 \mathrm{~K}$ (although the shape of the bands slightly alters), while subsequent increase of temperature causes reduction of its intensity (particularly evident changes start above 64 $\mathrm{K})$. Thus, aggregation of matrix-isolated Trp, similarly to what was formerly found for $\mathrm{Phe}^{23}$ and serine, ${ }^{20}$ is conformerdependent. In the conformers of type I both the $\mathrm{C}=\mathrm{O}$ group and the protons of the $\mathrm{NH}_{2}$ group are not involved in the intramolecular H-bond. That is why these conformers aggregate easier than conformers of type II, where the carbonyl oxygen atom is H-bonded with the protons of the amino group. Due to low overall abundance of conformers of type III, it is difficult to recognize how this form behaves during annealing, but it can be expected that it follows the same trend as in the case of type II conformers. During annealing, a growth of broad bands due to the aggregates, at ca. 1736 and $1713 \mathrm{~cm}^{-1}$, is observed, with the former growing more noticeably at higher temperatures and, therefore, being attributed to aggregates of conformers of types II and III. Note that the different temperature dependent behavior found for the band at $1781 \mathrm{~cm}^{-1}$ and the group of absorptions at 1766, 1762, and $1756 \mathrm{~cm}^{-1}$ does not give evidence of conformational isomerization. The opposite trend would be expected for this kind of processes: annealing should lead to increase of the population of the most stable type I conformers and then would require a growth of the band at 1781 $\mathrm{cm}^{-1}$ at the expense of the bands due to other forms.

Annealing of the Ar matrix was performed up to $38 \mathrm{~K}$ (Figure $7 b$ ). The bands attributed both to forms I (ca. $1786 \mathrm{~cm}^{-1}$ ) as well as to forms II and III $\left(1778,1772,1759 \mathrm{~cm}^{-1}\right)$ decrease in intensity starting from ca. $20-25 \mathrm{~K}$. These results suggest that aggregation is easier in argon matrix at $35 \mathrm{~K}$ compared with xenon matrix at $40 \mathrm{~K}$ (similar gas-to-compound ratio was achieved in both experiments). This behavior can be easily understandable because at temperatures around $35-40 \mathrm{~K}$ an argon matrix is already very plastic, with sublimation already taking place appreciably, while at these temperatures a xenon matrix still keeps its mechanical properties, in particular an appreciable rigidity.

\section{Conclusions}

The conformational behavior of Trp was investigated experimentally for the compound isolated in low-temperature argon and xenon matrixes by infrared spectroscopy and DFT(B3LYP)/6-311++G(d,p) calculations. A total of 42 minima have been located on the conformational space of Trp, with 17 of them in the $0-10 \mathrm{~kJ} \mathrm{~mol}^{-1}$ energy range relatively to the most stable form. The conformational distribution of tryptophan conformers at the temperature of sublimation of the compound $(473 \mathrm{~K})$ was calculated, and 14 rotamers were predicted to have abundances higher than $2 \%$. The order of relative energies of these conformers differs qualitatively from the order of their relative Gibbs energies, due to significant entropic effects. Two extremely low energy barriers for conformational interconversion have been found $\left(\mathrm{Ib}_{2}+\right.$ and $\mathrm{Ib}_{2}-$ into $\mathrm{Ib}_{1}+$ and $\mathrm{Ib}_{1}-$, respectively) reducing to 12 the number of conformers relevant from the viewpoint of the matrix isolation experiment.

The assignment of the experimental spectra was based on the calculated spectra of these 12 conformers. Although the detailed assignment should be treated as tentative, analysis of prominent spectral features unequivocally demonstrates the presence of at least two different types of conformers, $\mathrm{O}-\mathrm{H} \cdots \mathrm{N}$ hydrogen-bonded forms exhibiting the trans arrangement of the carboxylic group (type I) and type II/III featuring the $\mathrm{N}-\mathrm{H} \cdots \mathrm{O} \mathrm{H}$-bond and the cis conformation of the carboxylic group. Moreover, three individual conformers of type I ( Ia+, $\mathrm{Ib}+$, and $\mathrm{Ib}-$ ) were identified in both $\mathrm{Ar}$ and Xe matrixes, in agreement with the theoretical expectations. Annealing of the xenon matrixes resulted in conformer-selective aggregation of Trp, while no selectivity could be observed in the temperature range accessible to the argon matrix.

An extensive analysis of the geometry of the various possible conformers of Trp has been performed, revealing the importance of intramolecular hydrogen-bonding interactions, but also of the electrostatic interactions, in determining the relative stability of the different Trp conformers. The preference of the "plus" arrangement of the $\mathrm{C}_{\alpha}-\mathrm{C}_{\beta}-\mathrm{C}_{\gamma}=\mathrm{C}$ dihedral angle (around $+90^{\circ}$ ) over the "minus" geometry (around $-90^{\circ}$ ) was predicted by calculations for forms of type "a" and "b", while the reverse 
trend was noticed for forms of type "c", as it is noticed also for Trp residues in proteins. ${ }^{28}$ This fact demonstrates the increased importance of stabilizing interactions involving the pyrrole ring, as existing in the "a+" and "b+" forms as well as in the "c-" conformers, when compared with the analogous interactions involving the phenyl ring, which are present in the counterpart isomers ("a-", "b-", and "c+" forms).

Acknowledgment. Calculations were done at the Academic Computer Center "Cyfronet", Krakow, Poland (Grant KBN/ SGI_ORIGIN_2000/UJ/044/1999), which is acknowledged for computing time. The research was supported by the Portuguese Fundação para a Ciência e a Tecnologia (Grant FCT No. SFRH/ BPD/17081/2004 and Projects POCI/QUI/59019/2004 and POCI/QUI/58937/2004).

Supporting Information Available: Coordinates and total energies of all Trp conformers (Appendix 1S), definition of internal coordinates used in the normal-mode analysis of Trp (Table 1S), and assignments of experimental spectra of Trp isolated in an argon and xenon matrix (Table 2S). This material is available free of charge via the Internet at http://pubs.acs.org.

\section{References and Notes}

(1) Almlof, J.; Kvick, A.; Thomas, J. O. J. Chem. Phvs. 1973, 59, 3901-3906.

(2) Simpson, H. J.; Marsh, R. E. Acta Crystallogr. 1966, 20, 550.

(3) Freedman, T. B.; Diem, M.; Polavarapu, P. L.; Nafie, L. A. J. Am. Chem. Soc. 1982, 104, 3343-3349.

(4) Godfrey, P. D.; Brown, R. D.; Rodgers, F. M. J. Mol. Struct. 1996, $376,65-81$.

(5) Blanco, S.; Lesarri, A.; Lopez, J. C.; Alonso, J. L. J. Am. Chem. Soc. 2004, 126, 11675-11683.

(6) Lesarri, A.; Cocinero, E. J.; Lopez, J. C.; Alonso, J. L. Angew. Chem., Int. Ed. 2004, 43, 605-610.

(7) Lesarri, A.; Mata, S.; Cocinero, E. J.; Blanco, S.; Lopez, J. C.; Alonso, J. L. Angew. Chem., Int. Ed. 2002, 41, 4673-4676.

(8) Snoek, L. C.; Robertson, E. G.; Kroemer, R. T.; Simons, J. P. Chem. Phvs. Lett. 2000, 321, 49-56.

(9) Lee, K. T.; Sung, J.; Lee, K. J.; Kim, S. K.; Park, Y. D. J. Chem. Phvs. 2002, 116, 8251-8254.

(10) Lee, Y. H.; Jung, J. W.; Kim, B.; Butz, P.; Snoek, L. C.; Kroemer, R. T.; Simons, J. P. J. Phvs. Chem. A 2004, 108, 69-73.

(11) Snoek, L. C.; Kroemer, R. T.; Hockridge, M. R.; Simons, J. P. Phvs. Chem. Chem. Phvs. 2001, 3, 1819-1826.

(12) Bakker, J. M.; Aleese, L. M.; Meijer, G.; von Helden, G. Phvs. Rev. Lett. 2003, 91, 203003.

(13) Ivanov, A. Y.; Sheina, G.; Blagoi, Y. P. Spectrochim. Acta, Part A 1999, 55, 219-228.

(14) Stepanian, S. G.; Reva, I. D.; Radchenko, E. D.; Rosado, M. T. S.; Duarte, M.; Fausto, R.; Adamowicz, L. J. Phvs. Chem. A 1998, 102, 10411054.

(15) Stepanian, S. G.; Reva, I. D.; Radchenko, E. D.; Adamowicz, L. J. Phvs. Chem. A 1998, 102, 4623-4629.

(16) Lambie, B.; Ramaekers, R.; Maes, G. Spectrochim. Acta, Part A 2003, 59, 1387-1397.

(17) Stepanian, S. G.; Reva, I. D.; Radchenko, E. D.; Adamowicz, L. J. Phys. Chem. A 1999, 103, 4404-4412.

(18) Reva, I. D.; Stepanian, S. G.; Plokhotnichenko, A. M.; Radchenko, E. D.; Sheina, G. G.; Blagoi, Y. P. J. Mol. Struct. 1994, 318, 1-13.

(19) Stepanian, S. G.; Reva, I. D.; Radchenko, E. D.; Adamowicz, L. J. Phvs. Chem. A 2001, 105, 10664-10672.

(20) Jarmelo, S.; Lapinski, L.; Nowak, M. J.; Carey, P. R.; Fausto, R. J. Phvs. Chem. A 2005, 109, 5689-5707.

(21) Lambie, B.; Ramaekers, R.; Maes, G. J. Phys. Chem. A 2004, 108 , 10426-10433.

(22) Ramaekers, R.; Pajak, J.; Rospenk, M.; Maes, G. Spectrochim. Acta. Part A 2005, 61, 1347-1356.

(23) Kaczor, A.; Reva, I. D.; Proniewicz, L. M.; Fausto, R. J. Phys. Chem. A 2006, 110, 2360-2370.
(24) Sheina, G. G.; Radchenko, E. D.; Ivanov, A. Y.; Stepanyan, S. G.; Blagoi, Y. P. Zh. Fiz. Khim. 1988, 62, 985-990.

(25) Rizzo, T. R.; Park, Y. D.; Peteanu, L. A.; Levy, D. H. $\underline{\text { J. Chem. }}$ Phys. 1986, 84, 2534-2541.

(26) Martinez, S. J.; Alfano, J. C.; Levy, D. H. J. Mol. Spectrosc. 1992, $156,421-430$.

(27) Lee, K. T.; Sung, J. H.; Lee, K. J.; Kim, S. K.; Park, Y. D. Chem. Phvs. Lett. 2003, 368, 262-268.

(28) Petrella, R. J.; Karplus, M. Proteins: Struct. Funct., Bioinf. 2004, $54,716-726$.

(29) Huang, Z. J.; Lin, Z. J. J. Phys. Chem. A 2005, 109, 2656-2659. 202.

(30) Huang, Z. J.; Yu, W. B.; Lin, Z. J. J. Mol. Struct. 2006, 758, 195-

(31) Gordon, H. L.; Jarrell, H. C.; Szabo, A. G.; Willis, K. J.; Somorjai, R. L. J. Phys. Chem. 1992, 96, 1915-1921.

(32) Compagnon, I.; Hagemeister, F. C.; Antoine, R.; Rayane, D.; Broyer, M.; Dugourd, P.; Hudgins, R. R.; Jarrold, M. F. J. Am. Chem. Soc. 2001, 123, 8440-8441.

(33) Lindinger, A.; Toennies, J. P.; Vilesov, A. F. J. Chem. Phys. 1999 , $110,1429-1436$.

(34) Rizzo, T. R.; Park, Y. D.; Peteanu, L.; Levy, D. H. J. Chem. Phys. 1985, 83, 4819-4820.

(35) Reva, I. D.; Plokhotnichenko, A. M.; Stepanian, S. G.; Ivanov, A. Y.; Radchenko, E. D.; Sheina, G. G.; Blagoi, Y. P. Chem. Phvs. Lett. 1995 , $232,141-148$.

(36) Reva, I. D.; Plokhotnichenko, A. M.; Stepanian, S. G.; Ivanov, A. Y.; Radchenko, E. D.; Sheina, G. G.; Blagoi, Y. P. Chem. Phvs. Lett. 1995, $235,617-617$.

(37) Becke, A. D. Phvs. Rev. A 1988, 38, 3098-3100.

(38) Lee, C. T.; Yang, W. T.; Parr, R. G. Phvs. Rev. B 1988, 37, 785789.

(39) Peng, C. Y.; Schlegel, H. B. Isr. J. Chem. 1993, 33, 449-454.

(40) Peng, C. Y.; Ayala, P. Y.; Schlegel, H. B.; Frisch, M. J. J. Comput. Chem. 1996, 17, 49-56.

(41) Reva, I. A.; Jarmelo, S.; Lapinski, L.; Fausto, R. J.Phvs. Chem. A 2004, 108, 6982-6989.

(42) Frisch, M. J.; Trucks, G. W.; Schlegel, H. B.; Scuseria, G. E.; Robb, M. A.; Cheeseman, J. R.; Montgomery, J. A., Jr.; Vreven, T.; Kudin, K. N.; Burant, J. C.; Millam, J. M.; Iyengar, S. S.; Tomasi, J.; Barone, V.; Mennucci, B.; Cossi, M.; Scalmani, G.; Rega, N.; Petersson, G. A.; Nakatsuji, H.; Hada, M.; Ehara, M.; Toyota, K.; Fukuda, R.; Hasegawa, J.; Ishida, M.; Nakajima, T.; Honda, Y.; Kitao, O.; Nakai, H.; Klene, M.; Li, X.; Knox, J. E.; Hratchian, H. P.; Cross, J. B.; Bakken, V.; Adamo, C.; Jaramillo, J.; Gomperts, R.; Stratmann, R. E.; Yazyev, O.; Austin, A. J.; Cammi, R.; Pomelli, C.; Ochterski, J. W.; Ayala, P. Y.; Morokuma, K.; Voth, G. A.; Salvador, P.; Dannenberg, J. J.; Zakrzewski, V. G.; Dapprich, S.; Daniels, A. D.; Strain, M. C.; Farkas, O.; Malick, D. K.; Rabuck, A. D.; Raghavachari, K.; Foresman, J. B.; Ortiz, J. V.; Cui, Q.; Baboul, A. G.; Clifford, S.; Cioslowski, J.; Stefanov, B. B.; Liu, G.; Liashenko, A.; Piskorz, P.; Komaromi, I.; Martin, R. L.; Fox, D. J.; Keith, T.; Al-Laham, M. A.; Peng, C. Y.; Nanayakkara, A.; Challacombe, M.; Gill, P. M. W.; Johnson, B.; Chen, W.; Wong, M. W.; Gonzalez, C.; Pople, J. A. GAUSSIAN03; Gaussian, Inc.: Wallingford, CT, 2004.

(43) Pulay, P.; Fogarasi, G.; Pang, F.; Boggs, J. E. J. Am. Chem. Soc 1979, 101, 2550-2560.

(44) Martin, J. M. L.; Van Alsenoy, C. GAR2PED; University of Antwerp: Antwerp, Belgium, 1995.

(45) Engh, R. A.; Chen, L. X. Q.; Fleming, G. R. Chem. Phvs. Lett 1986, 126, 365-371.

(46) Chin, W.; Piuzzi, F.; Dimicoli, I.; Mons, M. Phvs. Chem. Chem. Phvs. 2006, 8, 1033-1048.

(47) Beierlein, F. R.; Othersen, O. G.; Lanig, H.; Schneider, S.; Clark, T. J. Am. Chem. Soc. 2006, 128, 5142-5152.

(48) Reva, I. D.; Ilieva, S. V.; Fausto, R. Phvs. Chem. Chem. Phvs 2001, 3, 4235-4241.

(49) Reva, I. D.; Stepanian, S. G.; Adamowicz, L.; Fausto, R. Chem. Phvs. Lett. 2003, 374, 631-638.

(50) Reva, I. A.; Lopes Jesus, A. J.; Rosado, M. T. S.; Fausto, R.; Eusébio, M. E.; Redinha, J. S. Phvs. Chem. Chem. Phvs. 2006, 8, 53395349.

(51) It must be noticed that the theoretically calculated spectra for the pairs of isomers $\left[\mathrm{Ib}_{2}+, \mathrm{Ib}_{2}-\right]$ and $\left[\mathrm{Ib}_{1}+, \mathrm{Ib}_{1}-\right]$ are very similar; therefore, the sum spectrum does not change substantially upon consideration of the isomerizations in question. 